\title{
Global Research Activity on E-Learning in Health Sciences Education: a Bibliometric Analysis
}

\author{
Waleed M. Sweileh ${ }^{1}$
}

Accepted: 16 February 2021 / Published online: 2 March 2021

(C) International Association of Medical Science Educators 2021

\begin{abstract}
Objective Progress in electronic learning (e-learning) and health sciences education is an indicator of the national and international efforts to achieve sustainable development goals regarding good health and quality education. The objective of the current study was to describe research volume and trends on e-learning in the health sciences education.

Methods A bibliometric methodology was adopted. The study period was from database inception until December 31, 2020. The data was downloaded from Scopus as a "csv" file. The data was analyzed to reveal prominent contributing countries, institution, authorship patterns, the degree of collaboration, international research collaboration, prominent sources for publications, frequent author keywords, the impact of research in terms of citations, and healthcare groups targeted in research. Results In total, 4576 records were retrieved. The analysis revealed an increasing growth in number of publications with time. There was a sharp peak in 2020. Recent literature on e-learning in health education included keywords such as flipped classroom, mobile learning, blended learning, and COVID-19. Countries in the European region and the region of the Americas have the highest contribution while countries in the African and the South-East Asian region have the least contribution. There was an increasing trend in the degree of author collaboration with time. However, the extent of international research collaboration was inadequate. The USA had the least percentage of documents with international authors (18\%) while Sweden had the highest (70.6\%). Documents published from Canada had the highest number of citations per document. The Karolinska Institute, based in Sweden, was the most active institution. The Medical Teacher journal ranked first in the number of publications while documents published in the Academic Medicine journal received the highest number of citations per document. The bulk of the retrieved literature was about medical or nursing education. The retrieved documents had an average of 12.7 citations per document and an H-index of 81 .

Conclusion Data presented can be used to develop and enhance e-learning in health sciences education in regions with poor research contribution. Policies regarding open access publications, international research collaboration, and adoption of e-learning methodologies in low- and middle-income countries need to be endorsed.
\end{abstract}

Keywords E-learning $\cdot$ Health education $\cdot$ Research $\cdot$ Bibliometrics

\section{Background}

The term electronic learning (e-learning) is relatively a recent and novel term that has evolved with the development and advancement of information and communication technologies (ICT). E-learning is considered a broad term

Waleed M. Sweileh

waleedsweileh@yahoo.com

1 Department of Physiology, Pharmacology/Toxicology, Division of Biomedical Sciences, College of Medicine and Health Sciences, An-Najah National University, Nablus, Palestine that describes the transfer of knowledge asynchronously or synchronously to learners using ICT [1]. The historical origin of the term e-learning is not exactly known. However, it started to flourish after the introduction of the Internet and personal computers. The University of Phoenix was the first school to offer courses on the Internet and introduced FlexNet, which combines online and classroom learning [2]. E-learning could be inside the classroom when using basic technology or completely outside the classroom as in the case of online universities. Currently, many universities use e-learning methods to complement traditional faceto-face teaching. This form is termed blended learning in which part of the learning activities occurs in the classroom 
and the remaining parts occur in the e-learning platform [3]. With the advancement of technology, mobile learning (m-learning) has emerged. M-learning is a portable and lightweight platform of e-learning in which the learner has no geographical constraint [4]. Both e-learning and m-learning are subsets of digital learning $[5,6]$.

The benefits of e-learning for students include the absence of time constraints for attending the lectures and the freedom to access lecture material at any time [7]. The e-learning increases global connectivity by facilitating connections across the globe and eliminate the physical boundaries of academic institutions [4]. At the institutional level, e-learning allows for the inclusion of a large number of students at minimum cost with increased quality of teaching materials. Therefore, e-learning made education more interesting, flexible, and broader.

Health sciences education is an important element in the sustainability of health services in any country. Medical schools provide the country with skilled health professionals and are an important source of health research targeted to improve health status and health standards of the country. However, medical education is expensive and requires human resources and physical infrastructure and might be interrupted as in the case of COVID-19. There is a growing interest among educators in the health field in e-learning [29]. Published research in this field compared the outcomes of e-learning with face-to-face education and showed broadly similar outcomes between e-learning and face-to-face education in medical schools $[9,15]$. This has generated a lot of enthusiasm among medical educators to implement e-learning methodologies for reasons related to cost and convenience given the outcomes of e-learning were broadly similar to that of face-to-face education [11, 43].

It is important to assess the ability of various countries and world regions to provide e-learning in health sciences education as an equitable and accessible method of learning. It is assumed that the lack of e-learning in any country is considered a drawback and weak adaptability of the education system to natural disasters or infectious disease outbreaks such as COVID-19. A potential indicator of the nation's ability to implement and adopt e-learning methodologies is the volume and quality of research publications on e-learning methods. Bibliometrics is defined as the application of mathematical and statistical methods to measure the research output of scholarly publications in a particular field [19]. The bibliometric analysis is an important tool in assessing research activity and research trends on a particular topic for future planning and financial allocation. Few published bibliometric studies investigated and assessed research activity on e-learning in general $[8,14,20]$. However, no bibliometric study was published on e-learning in health sciences education. Therefore, the objective of the current study was to assess research pattern and research trends on e-learning in health sciences education using the Scopus database for all the times up to the end of 2020.

\section{Method}

\section{Database}

This was a cross-sectional descriptive study conducted on February 02, 2022. The current study used the Scopus database to retrieve the relevant documents. Scopus database was previously used in several bibliometric studies because of the advantages it has over other scientific databases such as PubMed and Web of Science [12]. Scopus is the largest online database with abstracts and citations of over 23,700 peer-reviewed journals [12].

\section{Search Strategy}

The study period was all times up to December 31, 2020. The search strategy designed to retrieve relevant documents included five steps. Appendix 1 shows the search strategy and all relevant keywords used in the query.

1. First, keywords related to e-learning such as "blended learning", "online learning", and "mobile learning" were obtained from previously published systematic reviews and bibliometric studies on e-learning [13, 28, 39, 40]. The keywords on e-learning were used in combination with keywords related to health sciences education. Keywords related to health sciences education were obtained from a recently published systematic review in $B M C$ Medical Education journal [28].

2. Second, the keywords on e-learning were combined with the names of journals specialized in medical education such as "academic medicine", "advances in health sciences education", and "BMC medical education".

3. Third, the results obtained from the first and second step were combined.

4. Fourth, documents published in 2021 and false-positive documents were excluded. Only documents published in peer-reviewed scientific journals were included with no language restriction. Examples of false-positive documents include those containing the phrase "learning centers".

5. Fifth, keywords related to education such as education, student, and several others were added to the search query to minimize documents irrelevant to education.

\section{Validation and Quality Assurance of the Search Query}

The final overall search query was validated for the absence of false-positive results by sending an endnote file of randomly selected 100 documents to two independent colleagues. The colleagues assured the absence of false-positive 
results and that all documents were within the scope of the study. The search query was also validated for falsenegative results by investigating the research output of the top ten active authors and comparing the results with the actual number published by those authors. For example, the search query indicated that Cook, D.A. produced 33 documents, and when Scopus profile for Professor Cook, D.A, was checked, 34 documents related to e-learning were found. As another example, Professor Fischer, M.R., produced 28 documents based on the search query and had 29 documents in his Scopus profile related to e-learning. The same approach was carried out for other active authors and the obtained numbers were tested for correlation using the Pearson correlation test. The correlation was significant $(p=0.012)$ and the correlation coefficient $(r)$ was 0.93 indicative of a high correlation between the actual numbers and the ones obtained by the search query. This approach of validation was applied in previously published bibliometric studies [37].

\section{Bibliometric Indicators and Data Analysis}

Retrieved data was analyzed for the following bibliometric indicators: (1) annual growth, (2) active authors and author collaboration, (3) country and institution productivity, (4) active journals, (5) frequent author keywords, (6) geographic distribution of the retrieved literature, (7) target fields, and (8) subject areas.

The annual growth of publication was presented as a linear graph using Statistical Package for Social Sciences Program.

\section{Author Collaboration}

The degree of author collaboration reflects the extent of single-authored publication versus two or more authored publications. The degree of author collaboration does not reflect the extent of international research collaboration. The degree of author collaboration was calculated according to the following formula:

Degree of collaboration $(C)=\mathrm{Nm} / \mathrm{Nm}+\mathrm{Ns}$. where $\mathrm{Nm}=$ number of multi-authored papers and $\mathrm{Ns}=$ number of single-authored papers [21, 31].

\section{International Research Collaboration}

The degree of international research collaboration was assessed by calculating the intra-country (single-country publications $=\mathrm{SCP}$ ) and inter-country (international $=$ multi-country publications $=\mathrm{MCP}$ ) each country in the top active list. The percentage of MCP is an indicator for the extent of international research collaboration for that specific country. Both SCP and MCP were calculated from Scopus database directly.

The scientific impact of the publications was measured and compared using the number of citations per document as an indicator. Information about the number of citations was obtained from Scopus. The scientific impact of active journals was measured using the Hirsh index (H-index) of the journal as well as the number of citations for each document published in the journal. Information about $\mathrm{H}$-index of the journal and was obtained from Scimago website.

Mapping of author keywords was carried out using the free on-line program, VOSviewer software [41]. In the network visualization map, the node size is proportional to the frequency of occurrence. The network visualization maps could be presented in an overlay format in which the various terms in the map are given different colors with the yellow ones presenting the most recent terms.

The geographic distribution of the retrieved documents utilized the World Health Organization (WHO) world region classification: the region of the Americas, the European region, the African region, the Eastern Mediterranean region, the SouthEast Asian region, and the Western Pacific region.

\section{Results}

\section{General Description of the Retrieved Publications}

The search query on e-learning in health sciences education found 4576 documents. Approximately one third $(n=1594$, $34.8 \%$ ) of those were published in open access sources. The majority ( $n=3885,84.9 \%)$ of the retrieved documents were research articles, while the remaining documents were reviews, notes, letters, editorials, conference papers, and short surveys. English was the main language of publication $(n=4374$, 95.6\%), followed by German, Spanish, and Portuguese. The retrieved documents were cited 56,441 times, a mean of 12.4 citations per document, and an $h$-index of 81 .

\section{Subject Areas}

Social sciences $(n=2227,48.7 \%)$ was the most common subject area for publications, followed by medicine ( $n=1615,35.3 \%)$, nursing $(n=1089,23.8 \%)$, computer science $(n=326,7.1 \%)$, pharmacology/toxicology $(n=284$, $6.2 \%)$, health professions $(n=255,5.6 \%)$, biochemistry $(n=163,3.6 \%)$, and dentistry $(n=158,3.4 \%)$.

\section{Growth of Publications}

The retrieved documents were published from 1966 to 2020 . The highest number of publications was in $2020(n=534$, 
$11.7 \%$ ). The annual growth of publication remained very low from 1966 up to the year 2000 followed by a steep increase (Fig. 1). The number of documents published on e-learning in general was approximately 27,000 documents. Therefore, research on e-learning in health sciences education constitutes approximately $16.9 \%$ of the total research on e-learning.

\section{Most Frequent Author Keywords}

The most frequently encountered author keywords were e-learning ( $n=645$ occurrences), education $(n=288)$, blended learning ( $n=238)$, medical education $(n=255)$, online learning $(n=170)$, distance learning $(n=138)$, and nursing $(n=112)$. Figure 2 is an overlay visualization map of the top 50 frequent author keywords representing approximately $1 \%$ of the total number of author keywords $(n=5164)$ in the retrieved articles. The most recent author keywords were flipped classroom, COVID-19, mobile learning, and blended learning.

\section{Authorship Analysis and Top Publishing Authors}

In total, 14,552 authors contributed to the retrieved documents, a mean of 3.2 authors per document. Eighteen researchers $(0.4 \%)$ produced 10 or more documents. Table 1 shows the top ten productive authors. Dr. Cook, D.A, Professor at Mayo Medical School, Rochester, USA, was the most prolific author with 33 $(0.7 \%)$ and had the highest number of citations per document. In total, 792 publications (17.3\%) were single-authored and $1464(32.0 \%)$ publications were multi-authored ( $\geq 5$ authors). The degree of collaboration between authors in this field was
$82.7 \%$. The degree of author collaboration was $65.8 \%$ for documents published before 1999 and reached $89.3 \%$ for documents published from 2015 to 2020.

\section{Most Active Institutions}

Karolinska Institute (Sweden) ranked first with 75 (1.6\%) publications for each (Table 2). Documents published by authors in Mayo Medical School (USA) received the highest number ( $n=78.1)$ of citations per document. Five of the top active institutions were based in Europe, three in northern America, one in Latin America, and two in the Western Pacific region. The nonEuropean active institutions were based in Canada, Australia, and the USA.

\section{Top Active Countries}

In total, authors from 123 different countries contributed to the retrieved literature. However, $39.0 \%(n=48)$ of the countries contributed to 10 or more documents while 20 (16.3\%) countries contributed to only one document. Most publications came from the USA $(n=1407,30.7 \%)$, followed by the UK $(n=795$, $17.4 \%$ ). Table 3 shows the top ten productive countries along with citation analysis. Canada had the highest number of citations per document followed by that of Switzerland and the USA. The table also shows the extent of international research collaboration for each country. The USA had the least percentage (18.0\%) of documents with international authors while Switzerland had the highest percentage of documents with international authors $(70.6 \%)$.
Fig. 1 Annual growth of publications on e-learning in health sciences education

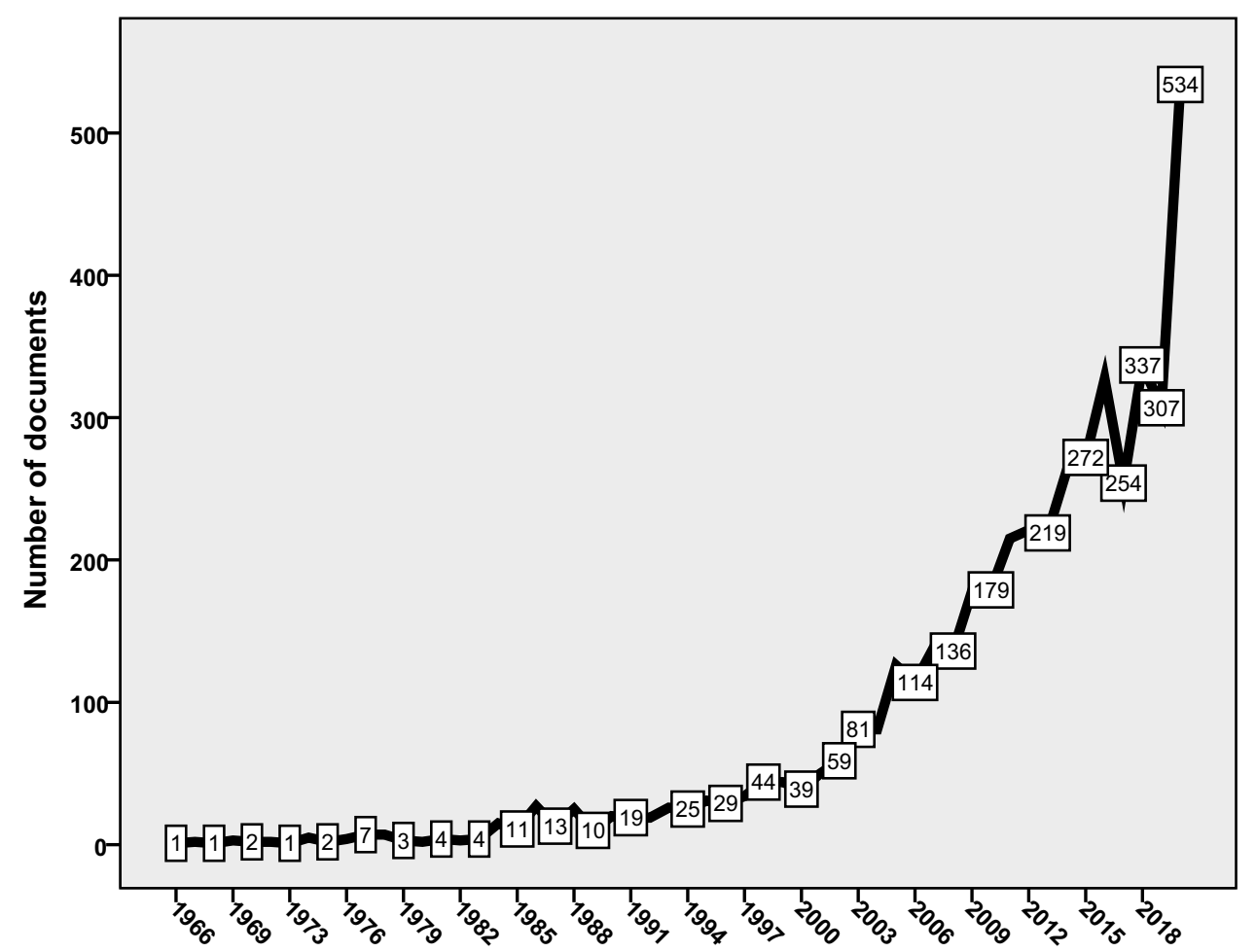




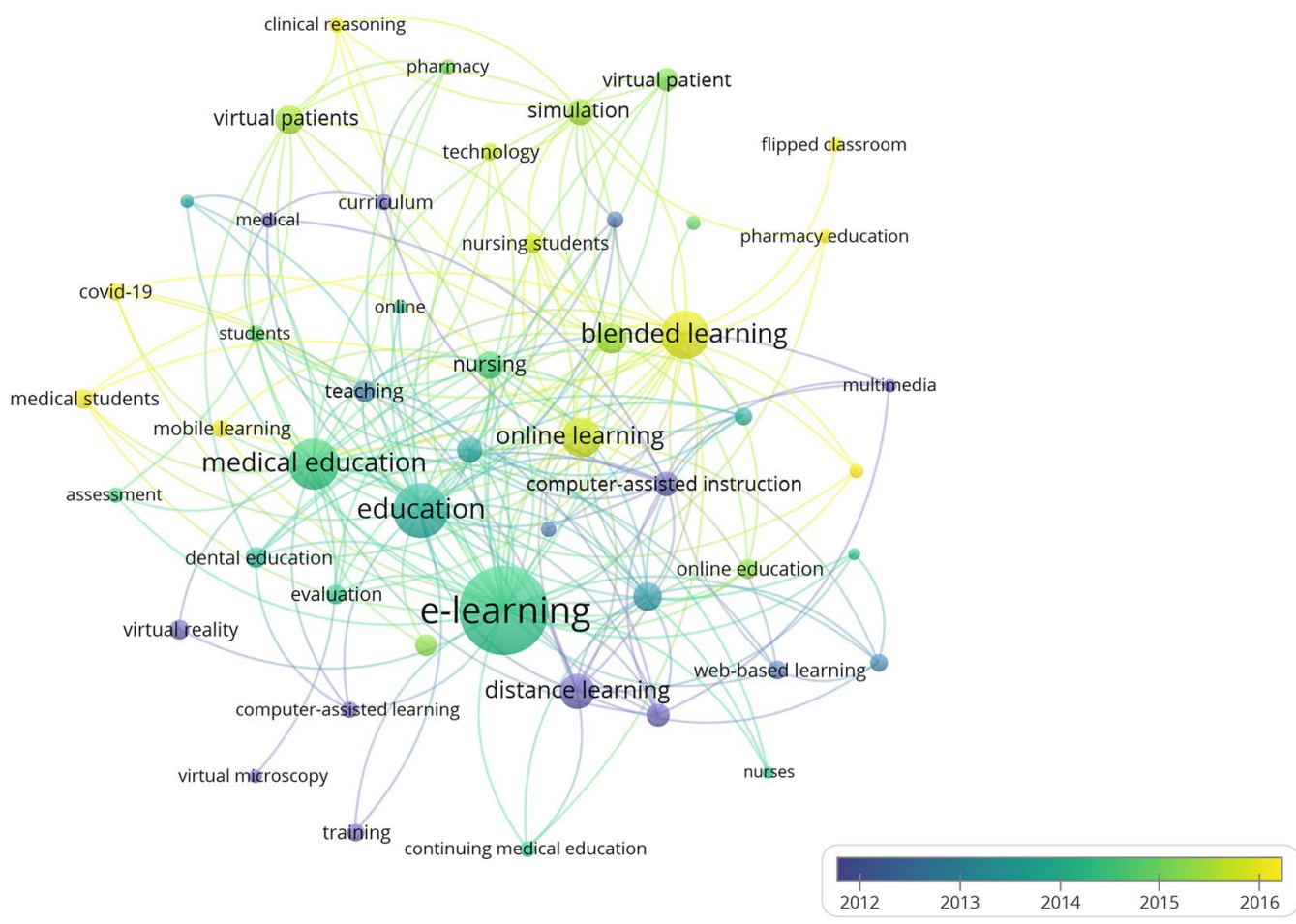

Fig. 2 Overlay network visualization map of top 50 author keywords that represent the top $1 \%$ of all author keywords in the retrieved articles ( $n=5164$ keywords). The colors in the map indicated the time of

\section{Geographic Distribution of the Retrieved Literature}

Countries in the European region and the region of the Americas had an approximately equal contribution to the retrieved literature (the European region $=39.3 \%, n=1799$; the region of the Americas $=39.2 \%, n=1796$ ). Countries in the African region made the least contribution $(n=104,2.3 \%)$. Figure 3 shows the annual growth of publications from different world regions. appearance in the literature with the yellow color indicating keywords that were relatively the most recent in literature

\section{Top Active Journals}

The retrieved documents were published in 1386 different journal titles. Only 53 (3.8\%) journals published 10 or more documents. "Medical Teacher", a journal focusing on medical education, was the most common source of publications ( $n=269$, $5.9 \%)$. This was followed by the journal of BMC Medical Education ( $n=237,5.2 \%)$ and "Nurse Education Today" $(n=211$,
Table 1 Top ten active authors in e-learning in health sciences education

\begin{tabular}{llllll}
\hline Rank & Author & $\begin{array}{l}\text { Number of } \\
\text { publications }\end{array}$ & $\% N=4576$ & $\begin{array}{l}\text { Number of citations } \\
\text { per document }\end{array}$ & $\begin{array}{l}\text { Current } \\
\text { Scopus } \\
\text { Affiliation }\end{array}$ \\
\hline 1st & Cook, D.A & 33 & 0.7 & 102.1 & USA \\
2nd & Zary, N & 28 & 0.6 & 20.3 & UAE \\
3rd & Fischer, M.R & 25 & 0.5 & 20.5 & Germany \\
4th & Hege, I & 21 & 0.5 & 14.0 & Germany \\
5th & Fors, U & 20 & 0.4 & 25.1 & Sweden \\
6th & Walsh, K & 19 & 0.5 & 4.0 & UK \\
7th & Huwendiek, S & 18 & 0.4 & 21.1 & Switzerland \\
8th & Harden, R.M & 17 & 0.4 & 20.3 & UK \\
9th & Sandars, J & 18 & 0.4 & 16.3 & UK \\
10th & Car, J & 15 & 0.3 & 16.1 & UK \\
10th & Kononowicz, A.A & 15 & 0.3 & 14.6 & Poland \\
10th & Lok, B & 15 & 0.3 & 30.5 & USA \\
\hline
\end{tabular}


Table 2 Top ten active institutions on e-learning in health sciences education

\begin{tabular}{llllll}
\hline Rank & Institute/organization & $\begin{array}{l}\text { Number of } \\
\text { publications }\end{array}$ & $\% N=4576$ & $\begin{array}{l}\text { Citations per } \\
\text { document }\end{array}$ & Affiliation \\
\hline 1st & Karolinska Institute & 75 & 1.6 & 16.7 & Sweden \\
2nd & $\begin{array}{l}\text { Ludwig Maximilian Univer- } \\
\text { sity of Munich }\end{array}$ & 53 & 1.2 & 16.0 & Germany \\
& Mayo Medical School & 46 & 1.0 & 78.1 & USA \\
3rd & University of Toronto & 46 & 1.0 & 12.6 & Canada \\
3rd & University of Leeds & 44 & 1.0 & 13.8 & UK \\
5th & Harvard Medical School & 40 & 0.9 & 23.5 & USA \\
6th & Monash University & 40 & 0.9 & 12.9 & Australia \\
6th & King's College London & 36 & 0.8 & 13.9 & UK \\
8th & The University of Sydney & 39 & 0.9 & 13.2 & Australia \\
9th & University Of São Paulo & 35 & 0.8 & 8.4 & Brazil \\
10th & & & &
\end{tabular}

4.6\%). Table 4 shows the list of top ten journals along with their citation analysis. There were four journals in the field of nursing education, five in medical/clinical education, and two in pharmacy education. Academic Medicine journal, based in the USA, had the highest $\mathrm{H}$-index and the highest number of citations per document. In total, 2247 (49.1\%) of the retrieved documents were published in journals within the scope of education while the remaining documents were published in journals in general medicine, public health, technology, and others.

\section{Target Groups}

The retrieved documents were analyzed for target groups. The majority of the documents were on medical/clinical education ( $n=2366,51.7 \%)$ followed by nursing $(n=1203,26.3 \%)$, health professionals in general $(n=682,14.9 \%)$, pharmacy education ( $n=401,8.8 \%)$, dental education $(n=232,5.0 \%)$, and veterinary education $(n=70,1.5 \%)$. Documents published in e-learning in medical education were mainly published in medical education journals. Similar findings were found regarding nursing and pharmacy education. Bibliographic coupling, which is a similarity measure, of top active journals showed three clusters of journals: medical journals, nursing journals, and pharmacy journals (Fig. 4).

\section{Discussion}

The current study aimed to investigate the peer-reviewed literature on e-learning in health sciences education using the Scopus database for all times up to 2020. The current study showed an increasing trend in the growth of literature with a sharp peak in 2020, mostly due to publications on e-learning during COVID19. This increase has been observed in the growth of literature on e-learning in general $[13,17]$. A recent study on global research trends on e-learning using Web of Science for the study period from 1989 to 2018 retrieved 9826 records with positive growth [17]. In the current study, the growth of publications was associated with an increasing trend in the degree of author collaboration. This suggests that e-learning in health sciences education
Table 3 Top ten active institutions in e-learning in health sciences education

\begin{tabular}{lllllll}
\hline Rank & Country & $\begin{array}{l}\text { Number of } \\
\text { publications }\end{array}$ & $\% N=4576$ & $\begin{array}{l}\text { Number of citations } \\
\text { per document }\end{array}$ & of SCP & \% of MCP \\
\hline 1st & USA & 1407 & 30.7 & 16.9 & 82.0 & 18.0 \\
2nd & UK & 795 & 17.4 & 14.0 & 77.6 & 22.4 \\
3rd & Australia & 314 & 6.9 & 11.3 & 73.9 & 26.1 \\
4th & Canada & 287 & 6.3 & 19.0 & 63.8 & 36.2 \\
5th & Germany & 280 & 6.1 & 13.3 & 66.4 & 33.6 \\
6th & Netherlands & 139 & 3.0 & 15.3 & 43.2 & 56.8 \\
7th & Sweden & 127 & 2.8 & 15.2 & 43.3 & 56.7 \\
8th & Brazil & 119 & 2.6 & 6.0 & 80.7 & 19.3 \\
9th & India & 96 & 2.1 & 4.3 & 78.1 & 21.9 \\
10th & Switzerland & 85 & 1.9 & 17.3 & 29.4 & 70.6 \\
\hline
\end{tabular}

$S C P$ single country publications = publications with all authors from the same country, $M C P$ multi country publications $=$ international research collaborations $=$ publications with authors from different countries 
Fig. 3 Annual growth of publication on e-learning in health sciences education in different world regions. The time line was specified from 1990 to 2020 because the number of publications before 1990 was minimal. Color codes: dark green: the region of the Americas; purple: the European region; black: the Western Pacific region; light green: the Eastern Mediterranean region; red: the South East Asian region; blue: the African region

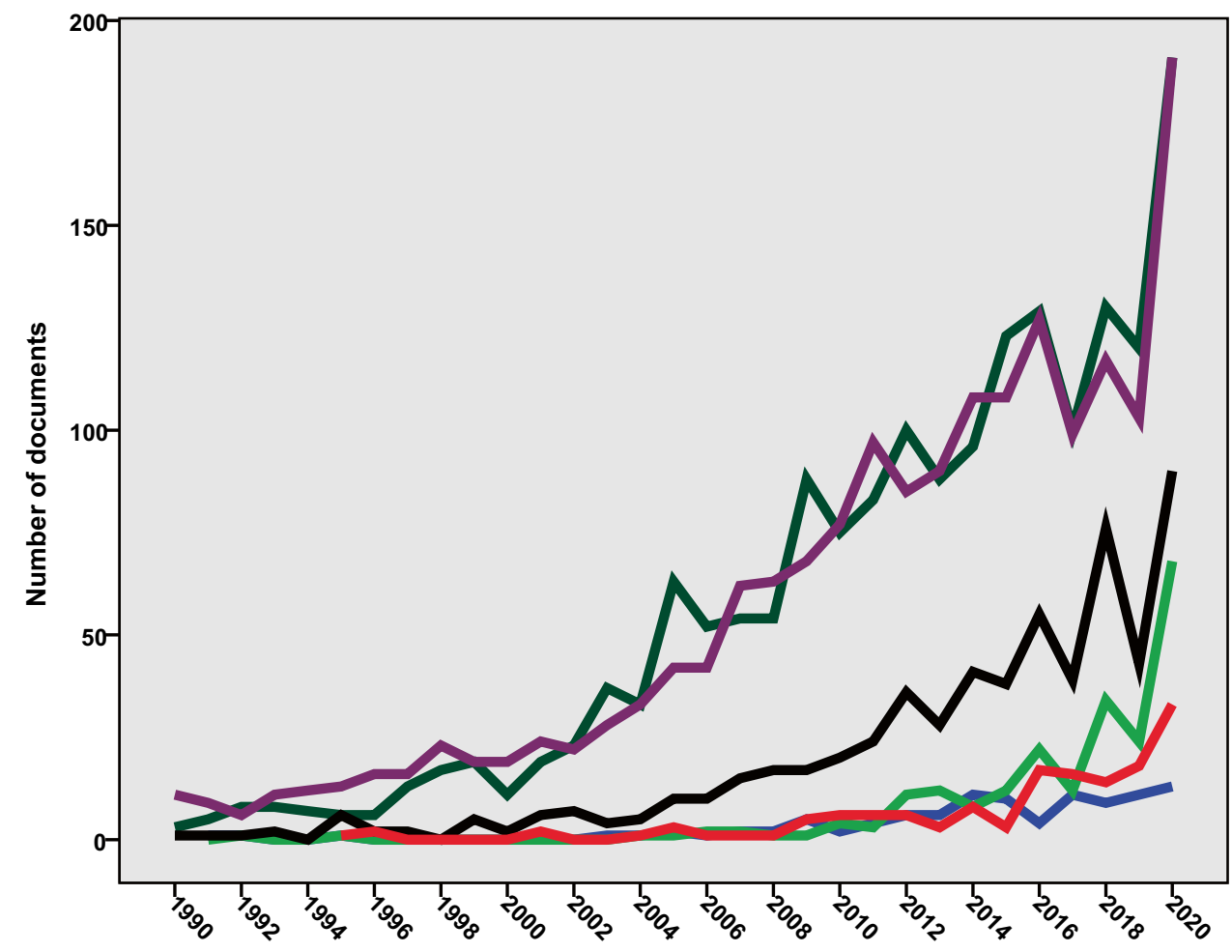

is attracting more researchers of different backgrounds. Research collaboration increases research productivity and academic entrepreneurship [10, 22]. However, the finding of the current study showed inadequate international research collaboration specifically for active countries. Inadequate research collaboration will limit the development of e-learning technologies and methods in low- and middle-income countries.

In the current study, approximately one third of all the retrieved articles were published in open access sources and the remaining were non-open access (subscription). Thus, open access publications were a minority. Open access publications are freely accessible at no charge, allowing barrier-free reading and spread of information and experiences of various research groups on e-learning. International initiatives, e.g., Budapest Open Science Initiative, support the transition toward open access publications to facilitate scientific communications. The limited open access publications on e-learning will also hinder the adoption of e-learning techniques and methods in low- and middle-income countries where access to full-text journals might be limited.

The current study indicated that the retrieved documents belonged to at least 10 different subject areas. This indicates

Table 4 Top ten active journals in e-learning in health sciences education

\begin{tabular}{|c|c|c|c|c|c|c|}
\hline Rank & Journal name & $\begin{array}{l}\text { Number of } \\
\text { publications }\end{array}$ & $\% N=4576$ & $\begin{array}{l}\text { Number of citations } \\
\text { per document }\end{array}$ & H-index & Country \\
\hline $1 \mathrm{st}$ & Medical Teacher & 269 & 5.9 & 17.9 & 101 & UK \\
\hline 2nd & BMC Medical Education & 237 & 5.2 & 16.2 & 61 & UK \\
\hline $3 \mathrm{rd}$ & Nurse Education Today & 211 & 4.6 & 17.0 & 72 & UK \\
\hline 4 th & Medical Education & 143 & 3.1 & 22.5 & 129 & UK \\
\hline 5 th & Academic Medicine & 109 & 2.4 & 39.7 & 143 & USA \\
\hline 6 th & American Journal Of Pharmaceutical Education & 93 & 2.0 & 15.7 & 58 & USA \\
\hline 7 th & Nurse Education In Practice & 88 & 1.9 & 8.6 & 43 & UK \\
\hline 8 th & Journal Of Nursing Education & 80 & 1.7 & 17.2 & 61 & USA \\
\hline 9 th & Journal Of Continuing Education In Nursing & 64 & 1.4 & 8.0 & 39 & USA \\
\hline 10th & Clinical Teacher & 60 & 1.3 & 5.7 & 23 & UK \\
\hline 10th & Currents In Pharmacy Teaching And Learning & 60 & 1.3 & 3.6 & 17 & Netherlands \\
\hline
\end{tabular}

$H$-index Hirsch index (obtained from Scimago) 


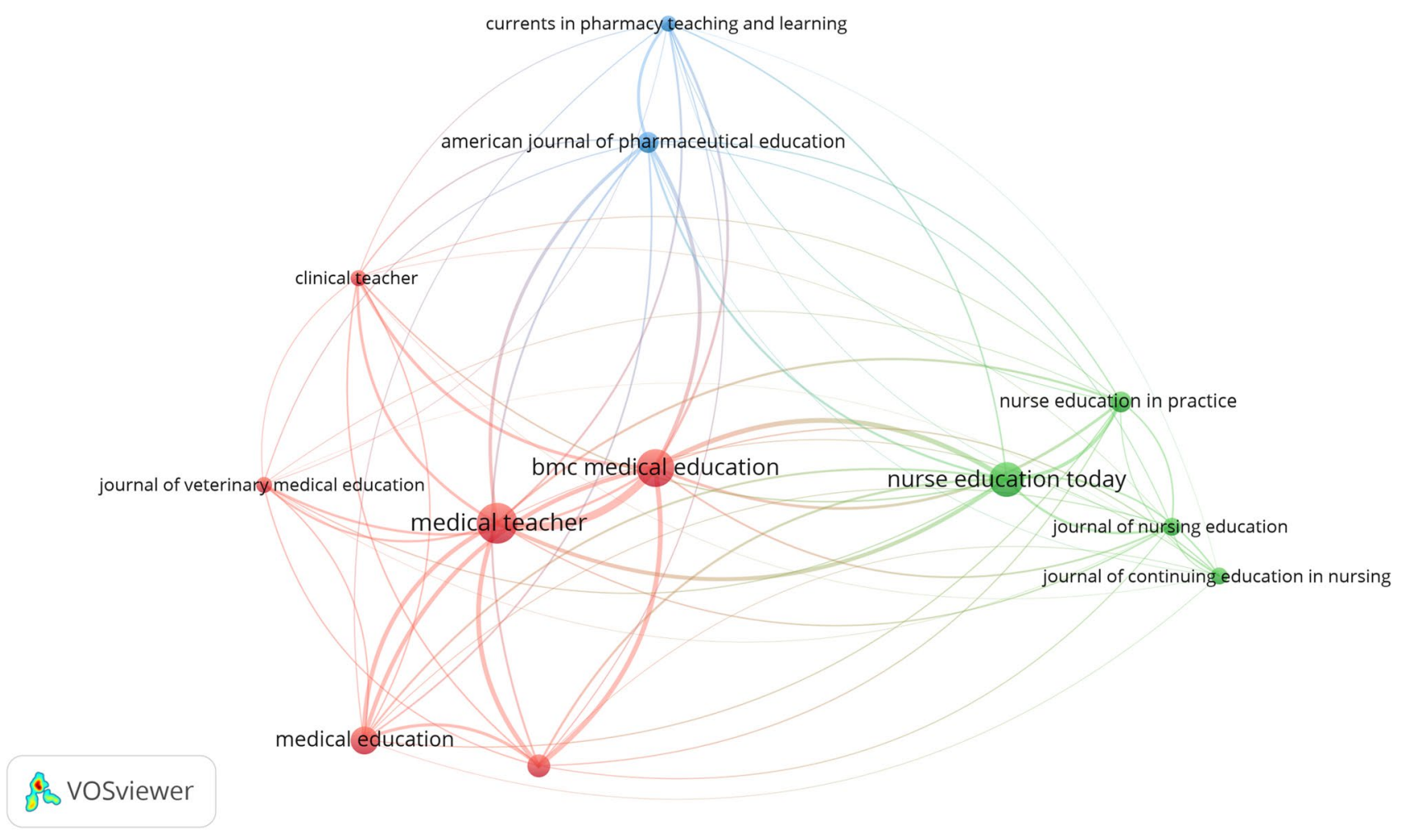

Fig. 4 Bibliographic coupling of top active journals. The map has three clusters. Each cluster represents journals with a common theme

that e-learning is a popular topic in education, medicine, nursing, pharmacy/pharmacology, computer sciences, dental, and veterinary medicine. E-learning is also used in continuing education for nurses, physicians, and pharmacists. It has been shown that e-learning is associated with a positive effect on knowledge, skills, and behavior of healthcare professionals, as well as on patient outcomes [16, 32].

Despite the popularity of e-learning, several factors have been listed as barriers for the development and implementation of online learning platform in health sciences. A recent study indicated that there are several barriers for online medical education in developing countries including poor technical skills, inadequate infrastructure, absence of institutional strategies and support and negative attitudes of all involved [25]. A study that investigated the barriers affecting the successful implementation of e-learning in Saudi Arabian universities indicated that infrastructure and technology dimension was the most significant barrier as perceived by respondents [26].

The current study indicated that author keywords such as flipped classroom, social media, and mobile learning were relatively most recent in the retrieved literature. The flipped classroom, which is a type of blended learning where students study the course material at home and practice working through it at school. Current evidence suggests that the flipped classroom approach in health profession education yields a significant improvement in student learning compared with traditional teaching methods [18]. This method was tested and medical students have generally expressed strong satisfaction with early applications of the flipped classroom to undergraduate medical education, and generally prefer this method to lecture-based instruction [27]. Another relatively recent author keyword in the e-learning literature was mobile learning in medical education. The advancement in technology led to the introduction of mobile learning which has its advantages and disadvantages. [42]. Mobile technology has become an important and popular tool in medical education [23].

The current study indicated that the majority of the retrieved publications were published by the top active countries. The leading role of the USA and the UK was also documented in e-learning research [17]. The current study indicated that most of the active countries were located in the northern hemisphere with limited contribution from the southern hemisphere. E-learning is a potential solution for many education-related problems of developing countries in the southern hemisphere, particularly those with a large population, large areas, and limited resources for establishing academic medical institutions. The same applies to the African region, SouthEastern Asian region, and the Eastern Mediterranean region. The advancement in technology and availability of needed infrastructure are the main reasons for the prominent contribution of the high-income countries to 
e-learning in health sciences in education. On the other hand, the poor infrastructure and poor information and communication technology are the main challenges for e-learning services and research in low- and moderateincome countries [24].

The current study showed that the retrieved documents received a relatively high number of citations per document and high $h$-index. This is indicative of the importance of the topic and the high level of interest of researchers in this field. This is not surprising given that the topic is not limited to a geographical area. Both health education and technology are top global priorities and embedded in the sustainable development goals. The number of citations is influenced by several factors including the extent of research collaboration which was high for the investigated topic [38]. The contribution of all world regions to the topic was also a positive factor for the increased number of citations. The finding that the majority of the top-cited documents were review articles and published in highly prestigious journals with high impact factors also played a positive role in the number of citations received by the retrieved documents. However, the fact that these prestigious journals were based in Europe might have created publication bias toward these countries [30].

In the current study, the majority of the retrieved documents were on medical and nursing education while the numbers of documents on pharmacy and veterinary education were the least. There are several peer-reviewed scientific journals in medical or nursing education. However, the number of peer-reviewed journals in the field of pharmacy or veterinary education was limited. This is one potential reason for the large volume of medical and nursing education literature compared with that in pharmacy or veterinary education. A second potential reason is the clinical aspects of the medical and nursing profession compared with that of the pharmacy profession. The keyword "virtual patient" is one of the top ten frequently encountered author keywords.

The results obtained in the current study regarding key players in e-learning in health sciences education does not match the results regarding key players in e-learning research in general. A recently published study indicated that in the 2003-2016 timespan, Taiwan, Japan, and China were listed among the top ten active countries in e-learning research productivity $[39,40]$. However, these countries did not show up in the top ten active countries in the current study. This suggests that e-learning in health sciences education is not of top priority in these countries. Furthermore, the top ten active institutions in e-learning, in general, were completely different than those in e-learning in health sciences education suggesting that different institutions might be actively involved in different subject areas in e-learning research $[39,40]$.

The current study is the first to investigate the global research activity on e-learning in health sciences education. The study shed light on key players in the field and showed the most recent topics of interest. However, the current study has a few limitations similar to other bibliometric studies [33-36]. The use of only one database to analyze research activity may limit the comprehensiveness of the retrieved data. The author believes that the use of Scopus database will cover the vast majority of documents published in PubMed and Web Science. However, documents on e-learning published in academic journals not indexed in international databases were not retrieved. The second limitation is the validity of the search query. The author used all possible and known validation methods to confirm the accuracy of the search query. However, the presence of false-positive or negative results remains a possibility.

\section{Conclusion}

The current study aimed to give an overview of the volume and research trends on e-learning in health sciences education. The analysis showed that this field is popular and characterized by an increasing degree of author collaboration from different subject areas, but with inadequate international research collaboration. The bulk of the research output was produced by high-income countries in the northern hemisphere with limited contribution from low-income world regions. E-learning research in the medical and nursing fields is progressing faster than other health sciences fields. There might be a need to launch new specialized journals in healthcare education in non-European and non-American regions. Such journals will serve to spread information and upgrade healthcare education systems in developing countries with limited resources. The advancement of technology will lead to new modalities in learning which might help overcome certain educational constraints in circumstances of natural or human-made disasters. International research collaboration in the field of e-learning in health education needs to be strengthened through governmental and non-governmental funding. Policymakers in lowand middle-income countries need to adopt regulations regarding e-learning methods in health education. Journal editors also need to follow the open-access policies in articles pertaining to e-learning methodologies to allow academics and researchers to have free access to published articles in order to implement such methodologies in health education. 


\section{Appendix 1 Search strategy and keywords}

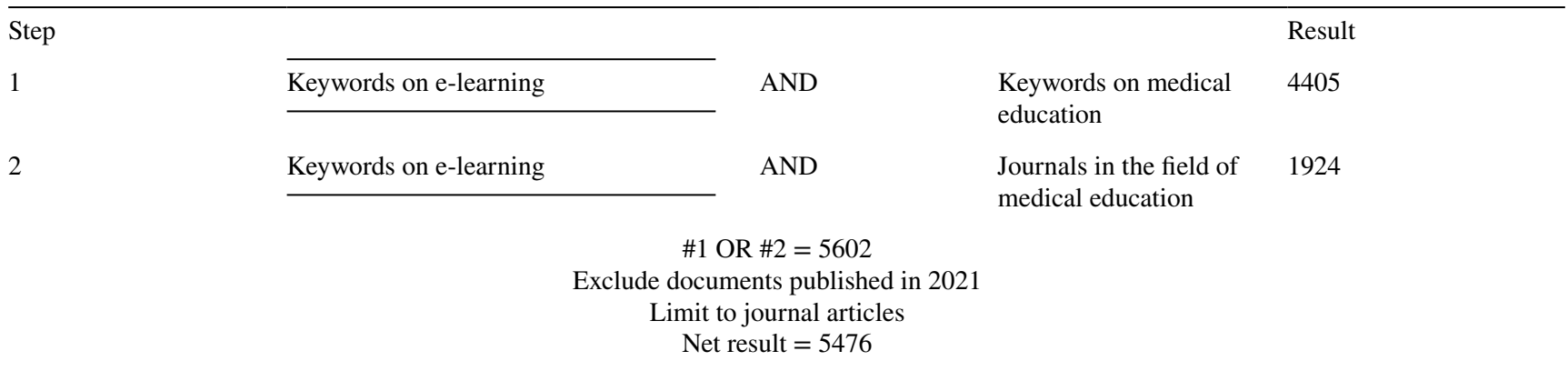

Keywords on e-learning

Keywords related to health/medical fields

Health/medical education journals "blended learning" or "b-learning" or "blearning" or "online learning" or "online education" or moocs or "massive open online courses" or m-learning or "mobile learning" or "mlearning" or "virtual learning" or "web-based learning" or "digital learning" or moodle or "e-learning" or "elearning" or "electronic learning" or "internet learning" or "distributed learning" or "network* learning" or "tele-learning" or "computer assisted learning" or "web-based learning" or "distance learning" or "learning management system" or "computer-based learning" or "interactive learning" or "learning management system " or "adaptive learning" or "electronic assessment" or "e-assessment" or "eassessment" or "interactive learning" or "web-based learning" or "digital learning" or "computer-assisted instruction" or "web-based learning" or "internet-based learning" or "multi-media learning" or "technology-enhanced learning" or "distributed learning" or "virtual patients" or "virtual microscopy" or "virtual environment" or "virtual learning"

medical or medicine or "clinical education" or nurs* or pharmac* or dental or pharmacolog* or "health profession*" or "public health" or "healthcare provider*" or "health* education" or dentistry or "continuing medical education" or "medical education" or "health sciences" or "medical sciences" or "public health education" or "nursing education" or "public health nursing" or "allied health education" or "health* worker*" or "contin* pharmacy education" or "contin* nurs* education"

"academic medicine" or "advances in health sciences education" or "bmc medical education" or "canadian medical education journal" or "clinical teacher" or "international journal of medical education" or "advances in medical education and practice" or "journal of graduate medical education" or "medical education" or "medical education online" or "medical teacher" or "perspectives on medical education" or "teaching and learning in medicine" or "nurs* education" or "academic nurse" or "education in nursing" or "nurse education today" or "pharmac* education" or "teaching and learning in medicine" or "teaching and learning in nursing" or "nurs* educator" or "pharmacy teaching" or "pharmacy learning" or "nurs* teaching"

\section{References}

1. Garrison DR. E-learning in the 21 st century: A community of inquiry framework for research and practice: Taylor \& Francis. 2016.

2. Swenson C, Myer D. University of Phoenix: a pioneer in online education. Sloan-C View. 2005;4(6):1-3.

3. Röhrig S, Hempel D, Stenger T, Armbruster W, Seibel A, Walcher F, Breitkreutz R. Which learning methods are expected for ultrasound training? Blended learning on trial Der Anaesthesist. 2014;63(10):745-52.

4. Gaur P. Research trends in e-learning. Media Communique. 2015;1(1):29-41.

5. Kumar Basak S, Wotto M, Belanger P. E-learning, M-learning and D-learning: conceptual definition and comparative analysis. E-Learning and Digital Media. 2018;15(4):191-216.

6. Rimale Z, El Habib BL, Tragha A. A brief survey and comparison of m-learning and e-learning. IJCNC. 2016;4(4):89.
7. Bouhnik D, Marcus T. Interaction in distance-learning courses. J Am Soc Inform Sci Technol. 2006;57(3):299-305.

8. Abubakar A B, HarandeZ Y I, Magaji, B. E-learning in Malaysia and Nigeria: A bibliometric study. Paper presented at the Proceedings of the 8th European Conference on e-Learning: ECEL. 2009.

9. Aker O, Hamooz S, Sweileh W. Effect of "Polypharmacy" and "Frequency of Drug Dosing" on Rate of Compliance among Diabetic and Hypertensive Patients: A Survey Study in Palestine. 2003.

10. Bozeman B, Fay D, Slade CP. Research collaboration in universities and academic entrepreneurship: the-state-of-the-art. J Technol Transf. 2013;38(1):1-67.

11. Brown C, Ross S, Cleland J, Walsh K. Money makes the (medical assessment) world go round: the cost of components of a summative final year Objective Structured Clinical Examination (OSCE). Med Teach. 2015;37(7):653-9. https://doi.org/10.3109/0142159X. 2015.1033389 . 
12. Burnham JF. Scopus database: a review. Biomed Digit Libr. 2006;3:1. https://doi.org/10.1186/1742-5581-3-1.

13. Cheng B, Wang M, Mørch AI, Chen NS, Spector JM. Research on e-learning in the workplace 2000-2012: a bibliometric analysis of the literature. Educ Res Rev. 2014;11:56-72.

14. Chiang JK, Kuo CW, Yang YH. A bibliometric study of e-learning literature on SSCI database. Paper presented at the International conference on technologies for E-learning and digital entertainment. 2010.

15. Cook DA, Levinson AJ, Garside S, Dupras DM, Erwin PJ, Montori VM. Internet-based learning in the health professions: a metaanalysis. JAMA. 2008;300(10):1181-96. https://doi.org/10.1001/ jama.300.10.1181.

16. Cook DA, Levinson AJ, Garside S, Dupras DM, Erwin PJ, Montori VM. Instructional design variations in internet-based learning for health professions education: a systematic review and metaanalysis. Acad Med. 2010;85(5):909-22. https://doi.org/10.1097/ ACM.0b013e3181d6c319.

17. Fatima N, Abu K. E-learning Research Papers in Web of Science: A Biliometric Analysis. Library Philosophy and Practice. 2019.

18. Hew KF, Lo CK. Flipped classroom improves student learning in health professions education: a meta-analysis. BMC Med Educ. 2018;18(1):38. https://doi.org/10.1186/s12909-018-1144-z.

19. Hicks D, Melkers J. Bibliometrics as a tool for research evaluation Handbook on the theory and practice of program evaluation: Edward Elgar Publishing. 2013.

20. Hung J. Trends of e-learning research from 2000 to 2008: use of text mining and bibliometrics. Br J Edu Technol. 2012;43(1):5-16.

21. Khaparde V. Authorship Pattern and Degree of Collaboration in Information Technology. JCSIT. 2013;1(1):46-54.

22. Lee S, Bozeman B. The impact of research collaboration on scientific productivity. Soc Stud Sci. 2005;35(5):673-702.

23. Masika MM, Omondi GB, Natembeya DS, Mugane EM, Bosire $\mathrm{KO}$, Kibwage IO. Use of mobile learning technology among final year medical students in Kenya. Pan Afr Med J. 2015;21(1).

24. Mtebe JS, Raphael C. A critical review of elearning research trends in Tanzania. Paper presented at the 2018 IST-Africa Week Conference (IST-Africa). 2018.

25. O'Doherty D, Dromey M, Lougheed J, Hannigan A, Last $\mathrm{J}$, McGrath D. Barriers and solutions to online learning in medical education-an integrative review. BMC Med Educ. 2018;18(1):130.

26. Quadri NN, Muhammed A, Sanober S, Qureshi MRN, Shah A. Barriers effecting successful implementation of E-learning in Saudi Arabian Universities. International Journal of Emerging Technologies in Learning (iJET). 2017;12(06):94-107.

27. Ramnanan CJ, Pound LD. Advances in medical education and practice: student perceptions of the flipped classroom. Adv Med Educ Pract. 2017;8:63-73. https://doi.org/10.2147/AMEP.S109037.

28. Regmi K, Jones L. A systematic review of the factors-enablers and barriers-affecting e-learning in health sciences education. BMC Med Educ. 2020;20:1-18.

29. Ruiz JG, Mintzer MJ, Leipzig RM. The impact of E-learning in medical education. Acad Med. 2006;81(3):207-12. https://doi. org/10.1097/00001888-200603000-00002.
30. Santeramo FG, Lamonaca E. The effects of non-tariff measures on agri-food trade: a review and meta-analysis of empirical evidence. J Agric Econ. 2019;70(3):595-617. https://doi.org/10.1111/14779552.12316.

31. Santha kumar R, Kaliyaperumal, K. A scientometric analysis of mobile technology publications. Scientometrics. 2015;105(2):921-39. https://doi.org/10.1007/s11192-015-1710-7.

32. Sinclair PM, Kable A, Levett-Jones T, Booth D. The effectiveness of Internet-based e-learning on clinician behaviour and patient outcomes: a systematic review. Int J Nurs Stud. 2016;57:70-81. https://doi.org/10.1016/j.ijnurstu.2016.01.011.

33. Sweileh WM. Global research trends of World Health Organization's top eight emerging pathogens. Global Health. 2017;13(1):9. https://doi.org/10.1186/s12992-017-0233-9.

34. Sweileh WM. Bibliometric analysis of global scientific literature on vaccine hesitancy in peer-reviewed journals (1990-2019). BMC Public Health. 2020a;20(1):1252. https://doi.org/10.1186/ s12889-020-09368-z.

35. Sweileh WM. Bibliometric analysis of peer-reviewed literature on climate change and human health with an emphasis on infectious diseases. Global Health. 2020b;16(1):44. https://doi.org/10.1186/ s12992-020-00576-1.

36. Sweileh WM. Health-related publications on people living in fragile states in the alert zone: a bibliometric analysis. Int J Ment Health Syst. 2020c;14:70. https://doi.org/10.1186/s13033-02000402-6.

37. Sweileh WM, Wickramage K, Pottie K, Hui C, Roberts B, Sawalha AF, Zyoud SH. Bibliometric analysis of global migration health research in peer-reviewed literature (2000-2016). BMC Public Health. 2018;18(1):777. https://doi.org/10.1186/s12889018-5689-x.

38. Tahamtan I, Afshar AS, Ahamdzadeh K. Factors affecting number of citations: a comprehensive review of the literature. Scientometrics. 2016;107(3):1195-225.

39. Tibaná-Herrera G, Fernández-Bajón MT, De-Moya-Anegón F. Output, collaboration and impact of e-learning research: Bibliometric analysis and visualizations at the country and institutional level (Scopus 2003-2016). El profesional de la información (EPI). 2018;27(5):1082-96.

40. Tibaná-Herrera G, Fernández-Bajón MT, De Moya-Anegón F. Categorization of E-learning as an emerging discipline in the world publication system: a bibliometric study in SCOPUS. Int J Educ Technol. 2018;15(1):1-23.

41. van Eck NJ, Waltman L. Software survey: VOSviewer, a computer program for bibliometric mapping. Scientometrics. 2010;84(2):523-38. https://doi.org/10.1007/s11192-009-0146-3.

42. Walsh K. Mobile learning in medical education: review. Ethiop J Health Sci. 2015;25(4):363-6. https://doi.org/10.4314/ejhs.v25i4.10.

43. Walsh K. Cost and value in e-learning: the perspective of the learner. BMJ Simul Technol Enhanc Learn. 2018;4(4):201-2.

Publisher's Note Springer Nature remains neutral with regard to jurisdictional claims in published maps and institutional affiliations. 